\title{
Urinary Neutrophil Gelatinase-Associated Lipocalin at Birth Predicts Early Renal Function in Very Low Birth Weight Infants
}

\author{
GAETANO LA MANNA, SILVIA GALLETTI, IRENE CAPELLI, SILVIA VANDINI, KATIA NISI, GIULIA AQUILANO, \\ RITA MANCINI, ELISA CARRETTA, GIOVANNI MONTINI, GIACOMO FALDELLA, AND SERGIO STEFONI
}

Department of Internal Medicine, Aging and Renal Disease [G.L.M., I.C., K.N., S.S.], Department of Woman Child and Adolescent Health [S.G., S.V., G.A., G.F.], Laboratory of Pathology and Clinical Chemistry [R.M.], Department of Pediatrics [G.M.], St. Orsola Hospital, University of Bologna, 40138 Bologna, Italy; Department of Medicine and Public Health [E.C.], University of Bologna, 40126 Bologna, Italy

\begin{abstract}
Preterm infants are exposed to conditions that can impair renal function. We evaluated the ability of serum and urinary neutrophil gelatinase-associated lipocalin (sNGAL and uNGAL) to predict renal function in the first weeks of life. From September 2008 to July 2009 , infants weighing $\leq 1500 \mathrm{~g}$ at birth with no major congenital anomalies or sepsis were eligible. We measured sNGAL and uNGAL levels at birth. To evaluate renal function, we determined changes in serum creatinine (sCreat) and estimated GFR (eGFR) from birth to d 21. Forty neonates (mean GA, $27 \pm 2 \mathrm{wk}$ ) completed the study. Renal function improved in 32 of $40(80 \%)$ infants (normal renal function, NRF group) (sCreat, from $0.97 \pm 0.2$ to $0.53 \pm 0.13 \mathrm{mg} / \mathrm{dL}$; eGFR, from $15.3 \pm 4.1$ to $28.6 \pm 7.9$ $\mathrm{mL} / \mathrm{min}$ ), whereas renal function worsened in 8 of $40(20 \%)$ infants (impaired renal function, IRF group) (sCreat, from $0.71 \pm 0.27$ to $0.98 \pm 0.43 \mathrm{mg} / \mathrm{dL}$; eGFR from $23 \pm 14.7$ to $16.4 \pm 9.1 \mathrm{~mL} / \mathrm{min}$ ). The uNGAL/urinary creatinine (uCreat) ratio at birth was higher in the IRF group (31.05 ng/mg) than the NRF group $(6.0 \mathrm{ng} / \mathrm{mg})$, and uNGAL was significantly higher in IRF group, detecting IRF with a cutoff of $100 \mathrm{ng} / \mathrm{mL}$. uNGAL levels at birth may have a predictive role in very LBW (VLBW) infants. (Pediatr Res 70: 379-383, 2011)
\end{abstract}

$\mathrm{T}$ he incidence of preterm birth is growing in developed countries. In addition, the survival rate for preterm infants has improved substantially $(1,2)$, from $74 \%$ in the 1980 s to $85 \%$ today $(3,4)$, with better results also for babies with very low GA. However, survivors have high rates of neonatal complications, neurodevelopmental problems, and long-term renal complications $(2,5-7)$.

Preterm infants are particularly susceptible to renal damage because they are born before week 36 of gestation, when the complex process of nephrogenesis is still incomplete (8). Moreover, in the first weeks of life, they are likely to experience complications or be exposed to therapies that can cause renal injury, including hypotension, hypoxia, mechanical ventilation, ibuprofen, or aminoglycoside infusion. The effects of these conditions/therapies on future renal function are not completely understood (9), but emerging epidemiologic data show that premature birth is associated with an increased incidence of hypertension (10-12), proteinuria, and chronic renal failure $(6,7,13)$ in adulthood. Furthermore, weight for

Received November 8, 2010; accepted April 7, 2011.

Correspondence: Gaetano La Manna, M.D., Ph.D., Nephrology Dialysis and Renal Transplantation Unit, Department of Internal Medicine, Aging and Renal Disease, University of Bologna, Via Massarenti 9, 40138 Bologna, Italy; e-mail: gaetano.lamanna@unibo.it
GA is a baseline predictor of kidney function and blood pressure in adulthood $(6,13,14)$.

During the first days of life, renal function is immature in very LBW (VLBW) infants, and its progressive development is influenced by maternal creatinine level and is proportionate to postnatal age, even in newborns of very low GA (15). Serum creatinine (sCreat), a marker of GFR, increases during the first $48 \mathrm{~h}$ of life, with a peak inversely related to birth weight (BW) and GA (16). The high level of sCreat during the first days of life is related to factors such as low glomerular filtration and increased tubular reabsorption caused by immature glomerular, tubular, and vascular structures. However, sCreat gradually decreases with improved renal function during the next 2 to $3 \mathrm{wk}$ (15).

Recently, several authors have reported that the injury biomarkers neutrophil gelatinase-associated lipocalin (NGAL) (17) and kidney injury molecule-1 (KIM-1) (18) may be useful to evaluate renal function in neonates. Two studies reported that in VLBW preterm infants, urinary NGAL (uNGAL) levels are inversely related to BW and GA $(19,20)$. However, the value of these biomarkers as predictors of renal function in very preterm infants has not yet been assessed.

The aim of this study was to evaluate prospectively the clinical and prognostic significance of these biomarkers at birth as predictors of renal function in the first weeks of life. We also evaluated possible associations between the new biomarkers and clinical factors of the first phases of life in VLBW neonates.

\section{METHODS}

Patients. Infants weighing $\leq 1500 \mathrm{~g}$ hospitalized in S. Orsola University Hospital NICU from September 2008 to July 2009 were eligible for the study. Exclusion criteria were major congenital anomalies, abnormal karyotype, sepsis at birth (C-reactive protein $>1.5 \mathrm{mg} / \mathrm{dL}$ or positive microbiological blood culture). The 5-min Apgar score was calculated for each infant, and prospective clinical data were obtained. The Apgar score is a method to assess

Abbreviations: AUC, area under the curve; BW, birth weight; eGFR, estimated glomerular filtration rate; IRF, impaired renal function; KIM-1, kidney injury molecule-1; NGAL, neutrophil gelatinase-associated lipocalin; NRF, normal renal function; PDA, patent ductus arteriosus; ROC, receiver operating characteristic; sCreat, serum creatinine; $\mathbf{S N G A L , ~ s e r u m ~ n e u t r o p h i l ~ g e l a - ~}$ tinase-associated lipocalin; uCreat, urinary creatinine; uNGAL, urinary neutrophil gelatinase-associated lipocalin; uKIM-1, urinary kidney injury molecule-1; VLBW, very LBW 
the health of newborn children 1 min and 5 min after birth. The Apgar score is determined by evaluating the newborn baby on five simple criteria (Appearance, Pulse, Grimace, Activity, and Respiration) on a scale from zero to two, then summing up the five values thus obtained. The resulting Apgar score ranges from 0 to 10 .

The protocol was approved by the S. Orsola University Hospital Ethics Committee, and parental consent for study participation was obtained during the first day of life.

Blood and urine collection. Blood and urine specimens were collected 24 to $48 \mathrm{~h}$ after birth. A blood specimen was also collected after $7 \mathrm{~d}$ and $3 \mathrm{wk}$ from birth for the determination of sCreat and the estimation of eGFR. Blood samples were collected in Vacutainer tubes (with clot activator and gel for serum separation). Serum was separated by centrifugation at $2500 \mathrm{rpm}$ for 15 min, and sCreat was assayed immediately. Aliquots of sera were frozen at $-20^{\circ} \mathrm{C}$ and analyzed subsequently to determine serum NGAL (sNGAL).

All urine samples were collected with a urine bag for $3 \mathrm{~h}$, and urinary creatinine (uCreat) was assayed immediately. Within $24 \mathrm{~h}$ of collection, the urine was centrifuged for $10 \mathrm{~min}$ at $1500 \mathrm{rpm}$. The supernatant was stored at $-20^{\circ} \mathrm{C}$ for successive determination of uNGAL and urinary KIM-1 (uKIM-1).

Laboratory assays. Creatinine was assayed from serum and urine specimens using Jaffè's method. The sCreat value was used to calculate the estimated GFR (eGFR) by applying Schwartz's formula, using the constant for preterm infant $(0.33)(21,22)$.

The levels of sNGAL, uNGAL, and uKIM-1 were measured by commercially available colorimetric sandwich ELISAs, using a DV 990 BV5UV microplate reader (GDV, Rome, Italy).

The determinations of NGAL in both urine and serum samples were performed using an NGAL ELISA Kit 036 (BioPorto Diagnostic, Grusbakken, Denmark) according to the manufacturer's instructions. The urinary levels of KIM-1 were determined by ELISA Kit for human KIM-1 (USCN Life Science Inc., Wuhan, People's Republic of China) according to the manufacturer's protocol. All specimens were diluted to obtain the concentration for the optimal density according to the instructions of the ELISA kit. Both serum and urinary NGAL levels were expressed in nanograms per milliliter. The detection limit was $<0.1 \mathrm{ng} / \mathrm{mL}$.

To account for the effect of urinary dilution, the concentration of uCreat was used to normalize uNGAL and uKIM-1 measurements.

Statistical analysis. Descriptive data are presented as mean \pm SD or number and percentage, and biomarker levels are expressed as median and range. The normal distribution of each continuous variable was verified by the Kolmogorov-Smirnov test.

Group demographic and clinical characteristics were compared by Wilcoxon test, $\chi^{2}$ test, or Fisher exact test, as appropriate, and renal function and biomarkers were compared by Wilcoxon test. Wilcoxon signed rank-sum test was used to analyze the variation in sCreat and eGFR at different follow-up examinations. Association among uNGAL, creatinine, and GFR values measured at birth and at $\mathrm{d} 21$ were evaluated by Spearman correlation. To assess the sensitivity and specificity of UNGAL as a predictor of renal impairment, receiver operating characteristic (ROC) curves were generated, and the area under the curve (AUC) was calculated. An AUC of 0.5 is no better than that expected by chance, whereas a value of 1.00 indicates an ideal biomarker. The level of significance in all cases was set at $p<0.05$. Statistical analyses were carried out using SAS 9.1 (SAS Institute, Cary, NC).

\section{RESULTS}

Patient characteristics. Between September 2008 and July 2009 , 55 preterm infants with a BW $\leq 1500$ g were hospitalized at the S. Orsola University Hospital NICU. We excluded infants with congenital anomalies $(n=4)$, infants who died in the first $48 \mathrm{~h}$ of life $(n=2)$, infants transferred to other units $(n=4)$, and those with incomplete data $(n=5)$. A total of 40 infants were eligible for the study: 16 infants were male $(40 \%)$, and eight (20\%) were small for GA, defined as BW below the 10th percentile according to the Italian Society of Neonatology growth curves (23). Mean BW was $956.8 \pm$ $305.9 \mathrm{~g}$ (range, 433-1487 g), and mean GA was $27 \pm 2 \mathrm{wk}$ (range, 22-32 wk). Three infants were assigned a 5-min Apgar score $<5$; one of the infants received a diagnosis of Grade 4 intraventricular hemorrhage.
Patent ductus arteriosus (PDA) was diagnosed by echocardiography in 26 infants $(65 \%) ; 14$ infants were treated with ibuprofen, and two infants underwent surgical ligation. Neonatal RDS was diagnosed in 27 infants (67.5\%); they were treated with mechanical ventilation $(51.9 \%)$ or nasal continuous positive airway pressure (48.1\%). Necrotizing enterocolitis was diagnosed in one infant. Thirty-one $(77.5 \%)$ neonates received aminoglycosides (Amikacin, $15 \mathrm{mg} / \mathrm{kg} / \mathrm{d}$ ) and 13 (32.5\%) received dopamine and/or dobutamine infusions. Two infants (5\%) developed hypotension, defined as blood pressure $>2$ SD below normal values for age and weight (24). Blood pressure was measured daily or several times a day, if necessary.

Renal function. At d 1, mean sCreat was $0.91 \pm 0.28$ $\mathrm{mg} / \mathrm{dL}$ and mean eGFR was $17.2 \pm 7.7 \mathrm{~mL} / \mathrm{min} / 1.73 \mathrm{~m}^{2}$; at d 7 , mean sCreat was $0.87 \pm 0.28 \mathrm{mg} / \mathrm{dL}$ and mean eGFR was $18.1 \pm 7.5 \mathrm{~mL} / \mathrm{min} / 1.73 \mathrm{~m}^{2}$; and at $\mathrm{d} 21$, mean sCreat was $0.61 \pm 0.28 \mathrm{mg} / \mathrm{dL}$ and mean eGFR was $26.2 \pm 9.4 \mathrm{~mL} / \mathrm{min} /$ $1.73 \mathrm{~m}^{2}$ (both $p<0.0001$ ). During the first $3 \mathrm{wk}$ of life, 32 neonates showed improved renal function, defined as a reduction in sCreat and increase in eGFR (normal renal function, $\mathrm{NRF}$ group): mean sCreat was $0.97 \pm 0.20 \mathrm{mg} / \mathrm{dL}$ at $\mathrm{d} 1$, $0.91 \pm 0.27 \mathrm{mg} / \mathrm{dL}$ at $\mathrm{d} 7$, and $0.53 \pm 0.13 \mathrm{mg} / \mathrm{dL}$ at $\mathrm{d} 21$; eGFR was $15.3 \pm 4.1 \mathrm{~mL} / \mathrm{min} / 1.73 \mathrm{~m}^{2}$ at $\mathrm{d} 1,17.1 \pm 6.3$ $\mathrm{mL} / \mathrm{min} / 1.73 \mathrm{~m}^{2}$ at $\mathrm{d} 7$, and $28.6 \pm 7.9 \mathrm{~mL} / \mathrm{min} / 1.73 \mathrm{~m}^{2}$ at $\mathrm{d}$ 21. In the other eight patients, sCreat increased from $\mathrm{d} 1$ to $\mathrm{d}$ 21 , and consequently eGFR decreased, demonstrating impaired renal function (IRF group): sCreat increased from $0.71 \pm 0.27 \mathrm{mg} / \mathrm{dL}$ at $\mathrm{d} 1$ to $0.78 \pm 0.36 \mathrm{mg} / \mathrm{dL}$ at d 7 and $0.98 \pm 0.43 \mathrm{mg} / \mathrm{dL}$ at $\mathrm{d} 21 ; \mathrm{eGFR}$ decreased from $23.0 \pm 14.7$ $\mathrm{mL} / \mathrm{min} / 1.73 \mathrm{~m}^{2}$ at $\mathrm{d} 1$ to $22.3 \pm 10.9 \mathrm{~mL} / \mathrm{min} / 1.73 \mathrm{~m}^{2}$ at $\mathrm{d} 7$ and $16.4 \pm 9.1 \mathrm{~mL} / \mathrm{min} / 1.73 \mathrm{~m}^{2}$ at $\mathrm{d} 21$.

As shown in Table 1, we compared the following demographic and clinical characteristics during the first days of life: BW, GA, sex, PDA, intrauterine growth retardation, mechanical ventilation, aminoglycoside administration, and inotropic infusions (dopamine/dobutamine). We found that dopamine and/or dobutamine infusion was more common in the IRF group ( $75 \%$ versus $21.9 \%, p=0.0085)$.

Renal function biomarkers. As depicted in Table 1, the median uNGAL level at $\mathrm{d} 1$ in the IRF group was significantly higher than that of the NRF group (IRF versus NRF: 236.6 versus $57.6 \mathrm{ng} / \mathrm{mL} ; p=0.0187$ ). The sNGAL levels were also higher, but the difference was not significant (IRF versus NRF: 110.1 versus $81.7 \mathrm{ng} / \mathrm{mL}, p=\mathrm{NS}$ ). The uKIM- 1 values did not differ significantly between the two groups (IRF versus NRF: 25.0 versus $42.8 \mathrm{ng} / \mathrm{mL}, p=\mathrm{NS}$ ). The concentrations of urinary biomarkers were normalized to uCreat concentration. The median uNGAL/uCreat value was significantly higher in the IRF group than the NRF group (IRF versus NRF: 32.5 versus $6.0 \mathrm{ng} / \mathrm{mg} ; p=0.0096)$. In contrast, the median uKIM-1/uCreat value was similar between groups (IRF versus NRF: 3.8 versus $4.3 \mathrm{ng} / \mathrm{mg}, p=\mathrm{NS}$ ). Moreover, high levels of UNGAL and IRF were not correlated with BW and GA in this study.

The uNGAL values at birth were positively correlated with differences in sCreat ( $r=0.51, p=0.0012$; Fig. 1$)$ and eGFR values $(r=-0.38, p=0.0190)$ from birth to $\mathrm{d} 21$. No 
Table 1. Demographic characteristics, clinical parameters, and biomarkers values of the infants

\begin{tabular}{|c|c|c|c|c|}
\hline & $\begin{array}{l}\text { All infants } \\
(n=40)\end{array}$ & $\begin{array}{l}\text { IRF group } \\
(n=8)\end{array}$ & $\begin{array}{l}\text { NRF group } \\
(n=32)\end{array}$ & $p$ \\
\hline Male, $n(\%)$ & $18(40 \%)$ & $3(37.5 \%)$ & $13(40.6 \%)$ & 1.000 \\
\hline BW, g & $956.8 \pm 305.9$ & $826.4 \pm 414.6$ & $989.4 \pm 271$ & 0.1680 \\
\hline GA, wk & $27.1 \pm 2.0$ & $26.5 \pm 3.7$ & $28.1 \pm 2.3$ & 0.1920 \\
\hline Intrauterine growth retardation, $n(\%)$ & $8(20 \%)$ & $1(12.5 \%)$ & $7(21.9 \%)$ & 1.000 \\
\hline $\mathrm{PDA}, n(\%)$ & $26(65 \%)$ & $3(37.5 \%)$ & $23(71.9 \%)$ & 0.1020 \\
\hline Mechanical ventilation and/or surfactant for RDS, $n(\%)$ & $27(67.5 \%)$ & $5(62.5 \%)$ & $22(68.7 \%)$ & 1.000 \\
\hline Ibuprofen treatment for PDA, $n(\%)$ & $14(35 \%)$ & $3(37.5 \%)$ & $11(34.4 \%)$ & 1.000 \\
\hline Aminoglycosides, $n(\%)$ & $31(77.5 \%)$ & $6(75 \%)$ & $25(78.1 \%)$ & 1.000 \\
\hline Dopamine and/or dobutamine, $n(\%)$ & $13(32.5 \%)$ & $6(75 \%)$ & $7(21.9 \%)$ & 0.0085 \\
\hline Hypotension at birth, $n(\%)$ & $2(5 \%)$ & $1(12.5 \%)$ & $1(3.1 \%)$ & 0.3640 \\
\hline uNGAL, ng/mL & $62.4(5.7-1301.0)$ & $236.6(107.1-601.4)$ & $57.6(5.7-1301.0)$ & 0.0187 \\
\hline $\mathrm{sNGAL}, \mathrm{ng} / \mathrm{mL}$ & $97.9(22.3-1267.0)$ & $110.1(37.8-747.4)$ & $81.7(22.3-1267.0)$ & 0.3566 \\
\hline $\mathrm{uKIM}-1, \mathrm{ng} / \mathrm{mL}$ & $41.4(10.8-381.3)$ & $25.0(13.2-381.3)$ & $42.8(10.8-287.1)$ & 0.6274 \\
\hline uNGAL/uCreat, ng/mg creatinine & $6.6(0.5-93.0)$ & $32.5(20.2-63.0)$ & $6.0(0.7-93.0)$ & 0.0096 \\
\hline uKIM-1/uCreat, ng/mg creatinine & $3.6(0.6-37.9)$ & $3.8(0.6-37.9)$ & $4.3(0.9-25.8)$ & 1.000 \\
\hline
\end{tabular}

Descriptive data are presented as mean \pm SD or absolute number with percentage; biomarker levels are expressed as median and range.

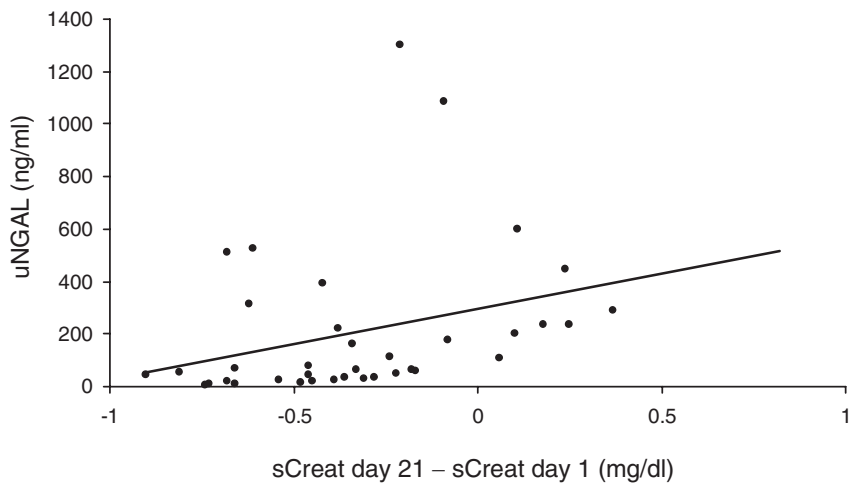

Figure 1. Spearman correlation plot between uNGAL at birth and differences in sCreat from birth to $\mathrm{d} 21(r=0.51, p=0.0012)$.

correlation was found between UNGAL values at birth and sCreat $(r=-0.27, p=0.1511)$ and eGFR at d $7(r=-0.24$, $p=0.2129)$.

Sensitivity and specificity of biomarkers. We compared the sensitivity and the specificity of UNGAL as an early marker of IRF in our population using four different cutoff values: 50 , 100,150 , or $200 \mathrm{ng} / \mathrm{mL}$ (Fig. 2). AUC was greater than 0.75 for cutoff values 100,150 , and $200 \mathrm{ng} / \mathrm{mL}$.

ROC curves were also plotted for sNGAL and uKIM-1. ROC analysis demonstrated that neither SNGAL nor uKIM-1 values adequately predicted creatinine changes in the first weeks of life in this study population (sNGAL AUC: 0.616, 95\% CI: 0.391-0.841; uKIM-1 AUC: $0.438,95 \%$ CI: $0.179-$ 0.697).

Mortality and prognosis. The mortality rate during the study period was $5 \%(n=2)$. Deaths were attributed to necrotizing enterocolitis (d 42) and pulmonary hypertension (d 29). Both infants were in the IRF group. BW was $<750 \mathrm{~g}$, and uNGAL at birth was higher than the cutoff value 100 $\mathrm{ng} / \mathrm{mL}$.

The morbidity of neonates was assessed in terms of days in the NICU. Infants in the IRF group spent a mean of $48.2 \mathrm{~d}$ in the NICU, whereas infants in the NRF group spent $35.5 \mathrm{~d}$ $(p=0.7)$. Neonates with uNGAL $>100 \mathrm{ng} / \mathrm{mL}$ at birth spent a mean of $44.2 \mathrm{~d}$ in the NICU, whereas neonates with uNGAL $<100 \mathrm{ng} / \mathrm{mL}$ at birth spent $27.8 \mathrm{~d}$ in the NICU $(p=0.09)$.

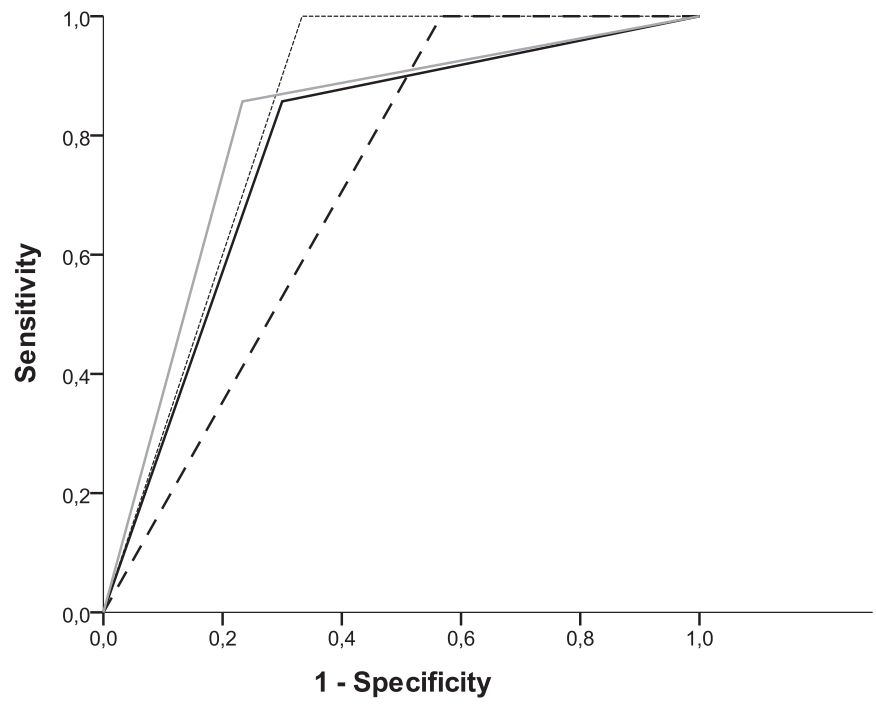

Figure 2. The sensitivity and specificity of uNGAL as a predictor of renal function in first 3 wk of life. The cutoff value of $50 \mathrm{ng} / \mathrm{mL}$ demonstrated sensitivity of $100 \%$ and a specificity of $43 \%$ (AUC: 0.717 ). The cutoff value of $100 \mathrm{ng} / \mathrm{mL}$ demonstrated sensitivity of $100 \%$ and a specificity of $67 \%$ (AUC: 0.833 ). The cutoff value of $150 \mathrm{ng} / \mathrm{mL}$ demonstrated sensitivity of $86 \%$ and a specificity of $70 \%$ (AUC: 0.779 ). The cutoff value of $200 \mathrm{ng} / \mathrm{mL}$ demonstrated sensitivity of $86 \%$ and a specificity of $77 \%$ (AUC: 0.812 ). ---, uNGAL $50 \mathrm{ng} / \mathrm{mL} ;---$, , uNGAL $100 \mathrm{ng} / \mathrm{mL} ;-$, uNGAL $150 \mathrm{ng} / \mathrm{mL} ;-$, uNGAL $200 \mathrm{ng} / \mathrm{mL}$

\section{DISCUSSION}

Premature birth increases the risk of medical and developmental problems, including IRF. Nephrogenesis begins at 5 wk gestation and is completed by 36 wk (8); $60 \%$ of all nephrons form during the third trimester (25). In premature infants, this complex process seems to continue after birth for $40 \mathrm{~d}$ (26), but it is not clear whether postnatal nephrogenesis is similar to intrauterine nephrogenesis.

Low BW is correlated with a reduced number of nephrons in humans (27). In nonhuman primates, ongoing nephrogenesis after preterm birth is associated with a normal rate of glomerular formation, but glomerular density is lower and the number of abnormal glomeruli is higher (28). Kidney function measurements in preterm infants reflect the kidney structure's 
immaturity at birth and typically show progressive development indicated by the concomitant increase in $\operatorname{GFR}(15,16)$. Thus, renal endowment in these infants can be affected by cardiac malformations (e.g. PDA), hypoxia, hypotension, nephrotoxic drugs (e.g. ibuprofen, aminoglycosides), and mechanical ventilation. The usual markers of kidney function are not able to identify preterm infants at risk for renal damage. To evaluate potential biomarkers in preterm infants at risk of developing kidney damage, this study focuses on the first $3 \mathrm{wk}$ of life of VLBW infants.

NGAL has been implicated in various physiological and pathological processes. Mishra et al. (17) have recently reported an increase in NGAL expression and urinary excretion in response to acute renal failure (ARF) secondary to ischemic injury. NGAL may also function as an iron-binding transporter modulating essential life processes. In addition, NGAL may play a role in cellular defense against toxic stimuli on kidney and other epithelia (29) and in nephrogenesis, as a mesenchymal differentiating factor produced by the ureteric bud (30).

In this study, most neonates (80\%, NRF group) showed increased eGFR during the first 3 wk of life, which is consistent with results reported by Gallini et al. (15) and Miall et al. (16). The other $20 \%$ of infants (IRF group) demonstrated stable or progressively deteriorating renal function. Both $\mathrm{uN}$ GAL levels and normalized uNGAL/uCreat values at birth were significantly higher in the IRF group than in the NRF group. In contrast, sNGAL and UKIM-1 were not significantly different between infants with NRF and those with IRF. In our population of VLBW infants, we found a positive correlation of UNGAL values at birth with differences in sCreat and eGFR values from birth to $\mathrm{d} 21$, but no correlation was found between uNGAL values at birth and sCreat and eGFR at $\mathrm{d} 7$. However, sCreat values at d 7 tended to increase in IRF group, and to decrease in NRF group, mirroring the trend of sCreat between $\mathrm{d} 1$ and $\mathrm{d} 21$. We can hypothesize that $7 \mathrm{~d}$ after birth is a too early time point to use UNGAL as a predictive measure of renal function in neonates.

ROC analysis revealed that the cutoff value of $100 \mathrm{ng} / \mathrm{mL}$ was able to identify neonates with IRF during the first weeks of life, with a specificity of $67 \%$ and a sensitivity of $100 \%$. This cutoff value is similar to that proposed to identify kidney damage in a recent meta-analysis of Haase et al. (31) and is higher than the reference range proposed by Huynh et al. (20) for VLBW infants with no risk factors for acute renal impairment. Our cutoff value seems to identify neonates with IRF in the first weeks of life and at risk for insufficient improvement of renal function.

In this study, IRF during the first weeks of life was not correlated with variables known to negatively influence renal function (hypotension, ibuprofen, mechanical ventilation, PDA, and intrauterine growth retardation) (32,33). This result may be due to the relatively small number of infants in this study and does not exclude the possibility that unknown factors affected renal function and NGAL in the first weeks of life. The higher usage of dopamine and dobutamine in the IRF group compared with the NRF group was the only significant clinical factor. However, the prevalence of hypotension in the first days of life was not higher in the IRF group. This finding may be due to the prevalence of hemodynamic factors in preterm infants that lead to the use of inotropic drugs, and the lack of a specific blood pressure threshold below which inotropic treatment is required. Thus, uNGAL may be a potential prognostic marker of hemodynamic instability. It is noteworthy that the mortality rate was higher in the IRF group than the NRF group ( $25 \%$ versus $0 \%$ ), in line with data from Walker et al. (34).

The increased uNGAL level in infants with IRF may be interpreted several ways. High NGAL levels may indicate prerenal ischemia, which can impair nephrogenesis in the first weeks of life. Alternatively, uNGAL values may indicate differentiation and growth of renal epithelium caused by immature nephrons, which stimulate glomerulogenesis. Our results cannot exclude the influence of other environmental, genetic, maternal, and inflammatory factors on uNGAL levels.

The use of creatinine and eGFR to determine renal function and the relatively small number of patients represent the principal limitations of our study. In addition, we evaluated only the first few weeks of life; therefore, we were not able to demonstrate that this period influences subsequent renal function in adulthood or nephron endowment, as reported by several authors, in terms of microalbuminuria, hypertension, chronic kidney disease, and cardiovascular disease $(14,35)$.

In conclusion, renal function in VLBW infants was associated with urinary NGAL levels in the first day of life. It is possible that ischemic damage of the renal parenchyma leads to diminished nephrogenesis in these infants, but we are not able to exclude the possibility that other factors (maternal, environmental, or genetic) might affect renal development and increase the risk of comorbidities in premature infants. Thus, using the cutoff value of $100 \mathrm{ng} / \mathrm{mL}$, uNGAL may be useful as a biomarker to identify VLBW neonates with IRF during the first 3 wk of life.

Acknowledgments. We acknowledge Dr. Maria Cappuccilli for the assistance given in the preparation of the manuscript.

\section{REFERENCES}

1. Martin JA, Hamilton BE, Sutton PD, Ventura SJ, Menacker F, Kirmeyer S, Munson ML Centers for Disease Control and Prevention National Center for Health Statistics National Vital Statistics System 2007 Births: final data for 2005. Natl Vital Stat Rep 56:1-103

2. Martin JA, Kung HC, Mathews TJ, Hoyert DL, Strobino DM, Guyer B, Sutton SR 2008 Annual summary of vital statistics: 2006. Pediatrics 121:788-801

3. Swamy GK, Ostbye T, Skjaerven R 2008 Association of preterm birth with longterm survival, reproduction and next generation preterm birth. JAMA 299:1429-1436

4. Tyson JE, Parikh NA, Langer J, Green C, Higgins RD National Institute of Child Health and Human Development Neonatal Research Network 2008 Intensive care for extreme prematurity - moving beyond gestational age. N Engl J Med 358:16721681

5. Larroque B, Ancel PY, Marret S, Marchand L, André M, Arnaud C, Pierrat V, Rozé JC, Messer J, Thiriez G, Burguet A, Picaud JC, Bréart G, Kaminski M EPIPAGE Study group 2008 Neurodevelopmental disabilities and special care of 5-year-old children born before 33 weeks of gestation (the EPIPAGE study): a longitudinal cohort study. Lancet 371:813-820

6. Hallan S, Euser AM, Irgens LM, Finken MJ, Holmen J, Dekker FW 2008 Effect of intrauterine growth restriction on kidney function at young adult age: the Nord Trøndelag Health (HUNT 2) Study. Am J Kidney Dis 51:10-20

7. Keijzer-Veen MG, Schrevel M, Finken MJ, Dekker FW, Nauta J, Hille ET, Frölich M, van der Heijden BJ Dutch POPS-19 Collaborative Study Group 2005 Microalbuminuria and lower glomerular filtration rate at young adult age in subjects born very premature and after intrauterine growth retardation. J Am Soc Nephrol 16:27622768 
8. Saxén L 1987 Organogenesis of the Kidney. Cambridge University Press, Cambridge, p 173

9. Ingelfinger JR, Schnaper HW 2005 Renal endowment: developmental origins of adult disease. J Am Soc Nephrol 16:2533-2536

10. Dalziel SR, Parag V, Rodgers A, Harding JE 2007 Cardiovascular risk factors at age 30 following pre-term birth. Int J Epidemiol 36:907-915

11. Johansson S, Iliadou A, Bergvall N, Tuvemo T, Norman M, Cnattingius S 2005 Risk of high blood pressure among young men increases with the degree of immaturity at birth. Circulation 112:3430-3436

12. Keijzer-Veen MG, Dülger A, Dekker FW, Nauta J, van der Heijden BJ 2010 Very preterm birth is a risk factor for increased systolic blood pressure at a young adult age. Pediatr Nephrol 25:509-516

13. Abitbol CL, Ingelfinger JR 2009 Nephron mass and cardiovascular and renal disease. Semin Nephrol 29:445-454

14. Ingelfinger JR 2008 Weight for gestational age as a baseline predictor of kidney function in adulthood. Am J Kidney Dis 51:1-4

15. Gallini F, Maggio L, Romagnoli C, Marrocco G, Tortorolo G 2000 Progression of renal function in preterm neonates with gestational age $<$ or $=32$ weeks. Pediatr Nephrol 15:119-124

16. Miall LS, Henderson MJ, Turner AJ, Brownlee KG, Brocklebank JT, Newell SJ, Allgar VL 1999 Plasma creatinine rises dramatically in the first 48 hours of life in preterm infants. Pediatrics 104:e76

17. Mishra J, Ma Q, Prada A, Mitsnefes M, Zahedi K, Yang J, Barasch J, Devarajan P 2003 Identification of neutrophil gelatinase-associated lipocalin as a novel early urinary biomarker for ischemic renal injury. J Am Soc Nephrol 14:2534-2543

18. Han WK, Bailly V, Abichandani R, Thadhani R, Bonventre JV 2002 Kidney Injury Molecule-1 (KIM-1): A novel biomarker for human renal proximal tubule injury. Kidney Int 62:237-244

19. Lavery AP, Meinzen-Derr JK, Anderson E, Ma Q, Bennett MR, Devarajan P, Schibler KR 2008 Urinary NGAL in premature infants. Pediatr Res 64:423-428

20. Huynh TK, Bateman DA, Parravicini E, Lorenz JM, Nemerofsky SL, Sise ME, Bowman TM, Polesana E, Barasch JM 2009 Reference values of urinary neutrophil gelatinose-associated lipocalin in very low birth weight infants. Pediatr Res 66:528 532

21. Schwartz GJ, Gauthier B 1985 A simple estimate of glomerular filtration rate in adolescent boys. J Pediatr 106:522-526

22. Schwartz GJ, Feld LG, Langford DJ 1984 A simple estimate of glomerular filtration rate in full-term infants during the first year of life. J Pediatr 104:849-854
23. Gagliardi L, Macagno F, Pedrotti D, Coraiola N, Furlan R, Agostini L, Milani S 1999 [Anthropometric neonatal standards provided by the task-force of the Italian Society of Neonatology based on a north-east Italian population]. Riv Ital Pediatr 25:159-169

24. Kent AL, Kecskes Z, Shadbolt B, Falk MC 2007 Normative blood pressure data in the early neonatal period. Pediatr Nephrol 22:1335-1341

25. Hinchliffe SA, Lynch MR, Sargent PH, Howard CV, Van Velzen D 1992 The effect of intrauterine growth retardation on the development of renal nephrons. Br J Obstet Gynaecol 99:296-301

26. Rodríguez MM, Gómez AH, Abitbol CL, Chandar JJ, Duara S, Zilleruelo GE 2004 Histomorphometric analysis of postnatal glomerulogenesis in extremely preterm infants. Pediatr Dev Pathol 7:17-25

27. Mañalich R, Reyes L, Herrera M, Melendi C, Fundora I 2000 Relationship between weight at birth and number and size of glomeruli in humans: a histomorphometric study. Kidney Int 58:770-773

28. Gubhaju L, Sutherland MR, Yoder BA, Zulli A, Bertram JF, Black MJ 2009 Is nephrogenesis affected by preterm birth? Studies in a non-human primate model. Am J Physiol Renal Physiol 297:F1668-F1677

29. Tong Z, Wu X, Ovcharenko D, Zhu J, Chen CS, Kehrer JP 2005 Neutrophil gelatinase-associated lipocalin as a survival factor. Biochem J 391:441-448

30. Yang J, Mori K, Li JY, Barasch J 2003 Iron, Lipocalin and kidney epithelia. Am J Physiol Renal Physiol 285:F9-F18

31. Haase M, Bellomo R, Devarajan P, Schlattmann P, Haase-Fielitz A; NGAL Metaanalysis Investigator Group 2009 Accuracy of neutrophil gelatinase-associated lipocalin (NGAL) in diagnosis and prognosis in acute kidney injury: a systematic review and meta-analysis. Am J Kidney Dis 54:1012-1024

32. Tóth-Heyn P, Drukker A, Guignard JP 2000 The stressed neonatal kidney: from pathophysiology to clinical management of neonatal vasomotor nephropathy. Pediatr Nephrol 14:227-239

33. Askenazi DJ, Ambalavanan N, Goldstain SL 2009 Acute kidney injury in critically ill newborns: what do we know? What do we need to learn? Pediatr Nephrol 24:265-274

34. Walker MW, Clark RH, Spitzer AR 2011 Elevation in plasma creatinine and renal failure in premature neonates without major anomalies: terminology, occurrence and factors associated with increased risk. J Perinatol 31:199-205

35. White SL, Perkovic V, Cass A, Chang CL, Poulter NR, Spector T, Haysom L, Craig JC, Salmi IA, Chadban SJ, Huxley RR 2009 Is low birth weight an antecedent of CKD in later life? A systematic review of observational studies. Am J Kidney Dis $54: 248-261$ 